\begin{tabular}{|l|l|l|l|l|l|}
\hline MUNIBE Antropologia-Arkeologia & $\mathrm{n}^{\circ} 66$ & $119-133$ & DONOSTIA & 2015 & ISSN $1132-2217 \bullet$ eISSN 2172-4555 \\
\hline
\end{tabular}

\title{
Completando el mapa de la Cuenca del Ebro: el Mesolítico del IX milenio cal BP de Espantalobos (Huesca, España)
}

\author{
Filling the Ebro Basin map: the Mesolithic levels of the \\ IXth millennium cal BP from Espantalobos (Huesca, Spain)
}

PALABRAS CLAVES: Mesolítico de Muescas y Denticulados; Mesolítico Geométrico; Cuenca del Ebro; Holoceno. GAKO-HITZAK: Mueska eta Horzdunen Mesolitoa; Mesolito Geometrikoa; Ebro ibarra; Holozenoa KEY WORDS: Denticulate Mesolithic; Geometric Mesolithic; Ebro Basin; Holocene.

\section{Lourdes MONTES(1), Rafael DOMINGO(2), José Antonio CUCHÍ(3), Marta ALCOLEA(2) \& Cristina SOLA(2)}

\section{RESUMEN}

Se presentan los resultados de la primera campaña de excavación de un nuevo yacimiento mesolítico, Espantalobos, en la Cuenca del Ebro. Localizado en las proximidades de la ciudad de Huesca, se trata de un abrigo de arenisca que conserva restos de dos ocupaciones humanas de las que la más reciente se relaciona con el Mesolítico Geométrico. Los escasos materiales del nivel más antiguo, sin embargo, no permiten de momento decidir su adscripción a esta fase o a su predecesora de Muescas y Denticulados, y tampoco su datación, bisagra entre ambas etapas. Pese al pobre estado de conservación del sitio fuertemente afectado por tareas de cantería y por la erosión, se han recuperado, además de los habituales materiales líticos, algunos restos de fauna y un interesante lote de carbones cuyo análisis antracológico permite paliar en parte la ausencia de datos de polen, que no se ha conservado.

\section{LABURPENA}

Ebro ibarreko Espantalobos Mesolito garaiko aztarnategi berriaren lehen indusketa-kanpainaren emaitzak aurkeztuko dira. Huesca hiritik gertu, harearrizko babesleku honek bi giza okupazioren aztarnak kontserbatzen ditu; bietako berriena Mesolito Geometrikoarekin erlazionatzen da. Maila zaharreneko material gutxi dagoenez, oraingoz ezin daiteke erabaki fase horretan edo aurrekoan (Mueskak eta Horzdunak izenekoa) atxiki beharko litzatekeen. Gainera, bi etapen arteko tarteari dagokion datazioa ere ezin daiteke finkatu. Harrobi-lanek eta higadurak gogor kaltetutako lekuaren kontserbazio-egoera txarra izan arren, ohiko harri-materialez gain, fauna aztarna batzuk eta ikatz multzo interesgarri bat berreskuratu ahal izan dira. Horien azterketa antrakologikoari esker, neurri batean, polenaren datuak ez izatearen zailtasuna gainditu ahal izan dugu, ez baita halakorik kontserbatu.

\section{ABSTRACT}

This paper presents the results of the first archaeological campaign in Espantalobos, a new Mesolithic site in the Ebro Basin. Located next to the city of Huesca, it helps to improve our knowledge on the prehistoric occupation of plains, non-mountainous areas, which in the central Ebro Basin have suffered a deep transformation in historic times due to agriculture and erosive processes related to anthropic deforestation. Its main contribution to the prehistoric research is the archaeological confirmation of the occupation by groups of hunter-gatherers of lowland areas during Mesolithic times.

The site is a dismantled sandstone rock-shelter that shows two different human occupations. The most recent archaeological layer (level c) is related to the Geometric Mesolithic: its lithic industry is based on laminar elements, which were brought to the site already knapped, and some retouched elements, mainly elongated trapezes and microburins, typical of the first Geometric Mesolithic moments in the Ebro Basin. However, the scarce elements from the former level e, just two geometrics and some notched flakes, make difficult to ascribe the occupation to this phase or to the previous Denticulate Mesolithic. In both periods lithic raw materials could have been collected in nearby areas, barely $30 \mathrm{~km}$ to the south of the site, where outcrops of a good-quality "Monegros-type" flint are known. Prehistoric people also knapped non-siliceous local rocks to obtain flakes, which were used untransformed. They also profited these boulders and pebbles to obtain heavy, resilient tools (choppers, rabot).

Despite the poor conservation of the site -strongly affected by quarrying activities and erosion-, an interesting toolkit has been found, as well as some faunal remains and a copious lot of charcoals whose anthracological data can partially replace the missing pollen analysis, which is not conserved in the sediment. In this type of shelters bad conservation of bone assemblage is usual: a poor sample of Capra, Cervus and Oryctolagus has been identified, many of them cremated on purpose, while an ibex bone presents a cut mark.

The radiocarbon dates place the human occupations in the Early/Middle Holocene: level e (8975-8547 cal BP) coincides with the final phases of the Climatic Optimum, and level c (8321-8046 cal BP) fit with the interesting dry and cold 8.2 event. After this data, level e could be-

\footnotetext{
(1) Universidad de Zaragoza. Área de Prehistoria. Facultad de Ciencias Humanas y de la Educación. Plaza de la Constitución s/n. 22001 Huesca Imontes@unizar.es

(2) Universidad de Zaragoza. Área de Prehistoria. Facultad de Filosofía y Letras.

(3) Universidad de Zaragoza. Área de Ingeniería Agroforestal. Escuela Politécnica Superior de Huesca.
} 
Iong either to a final Denticulate Mesolithic or to an early Geometric Mesolithic: as far as we know, this last period starts around these times in the left bank of the Ebro Basin.

Concerning charcoals, a first approach to their comprehensive study is offered. Level $c$ could reflect the 8.2 event by the retrocession of mesophilous taxa and the increase of xerophilous species compared to level e, being conifers (Pinus and Juniperus) the most frequent taxa in both layers, in an open landscape previous to the expansion of the Quercus genera.

Espantalobos could be interpreted, like other small rock shelters with similar occupations, as a seasonal settlement, dedicated to exploit one or more specific resources (still not determined), repeatedly occupied by a small party of people. Espantalobos, like Cabezo de la Cruz campsite in the Huerva Valley, confirms the presence of Mesolithic people in the currently eroded and humanized plains of the central Ebro Basin. It helps to articulate a growing network of prehistoric sites that make this region one the best areas in Iberia to study the Early/Middle Holocene.

\section{1.- INTRODUCCIÓN}

El sitio de Espantalobos (Quicena, Huesca) es un asentamiento mesolítico localizado en malas condiciones de conservación, prácticamente a punto a desaparecer, que amplía la nutrida red de yacimientos de esta época en la Cuenca del Ebro (UTRILLA et al. 2009; ALDAY et al. 2014). Espantalobos contribuye a rellenar el mapa de la cuenca al sur de las estribaciones montañosas pre-pirenaicas, confirmando, como antes lo hiciera el campamento del Cabezo de la Cruz en el valle del Huerva (RODANÉS y PICAZO, 2009, 2013), que estos cazadores-recolectores se movían igualmente en las zonas Ilanas. El yacimiento fue localizado en los años 80, cuando D. I. Gracia, vecino de Huesca, recogió en un barranco próximo a Quicena una serie de restos líticos -varios geométricos de retoque abrupto y láminas de sílex intactas- que sugerían la existencia de un yacimiento cuya erosión hacía aflorar los materiales. A finales de 2012 se determinó el posible foco de origen y en el verano de 2013 se llevó a cabo la primera campaña de excavación, cuyos resultados se presentan ahora.

\section{2.- EL YACIMIENTO Y SU EXCAVACIÓN}

El yacimiento se encuentra en la zona conocida como Las Canteras de Quicena, al norte de este núcleo urbano y muy próxima al mismo (Figura 1), a 500 metros de altitud. Se localiza en la ladera de un barranco activo cuyo nombre se ha tomado para el yacimiento: Espantalobos. Esta zona, situada al pie del castillo medieval de Montearagón, recibe el nombre genérico de Las Canteras por haber abastecido de piedra arenisca a su entorno en tiempos históricos: al núcleo de Quicena y a la inmediata fortalezaabadía, pero probablemente también a la ciudad de Huesca de la que dista unos 4 km (CUCHí et al. 2005: 165). La erosión y las tareas de cantería habituales en la zona han desmontado casi por completo el paleocanal de arenisca que ofreció refugio a las gentes prehistóricas: un roquedo orientado a sol naciente en el que guarecerse, que quizás nunca presentó una gran visera de protección pero que resguardaba el sitio de los vientos dominantes.

Una vez gestionado el permiso oficial, la excavación se desarrolló entre el 17 y el 28 de junio de 2013 bajo la dirección de Rafael Domingo y Lourdes Montes. Marta Al-

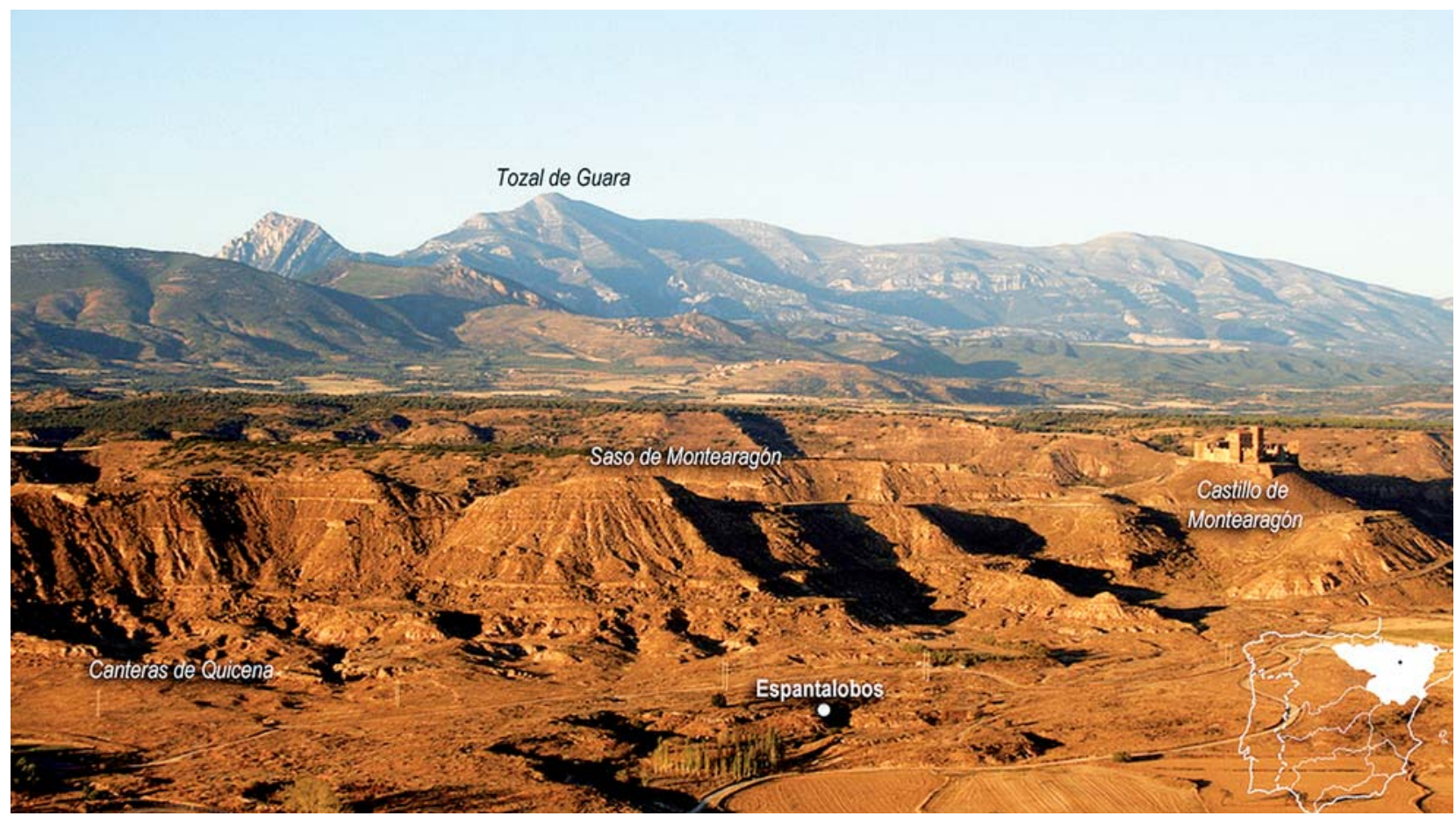

Fig. 1. El yacimiento de Espantalobos y principales resaltes del entorno / The site of Espantalobos and main reliefs of its surroundings (Photo: F. Navajas). 
colea y Cristina Sola se hicieron cargo respectivamente del estudio antracológico y paleontológico y José Antonio Cuchí, de la Universidad de Zaragoza, de la sedimentología del sitio y de la geomorfología del entorno. Penélope González-Sampériz, del Instituto Pirenaico de Ecología-CSIC, tomó 9 muestras para el análisis palinológico, que resultaron estériles. La cuadrícula se acomodó al buzamiento natural de la ladera (Figura 2) y el trabajo de extracción de las tierras se realizó por sectores de $33 \mathrm{~cm}$ de lado ( 9 en cada cuadro de metro de lado) y semitallas de $5 \mathrm{~cm}$ siguiendo los niveles naturales del registro. La diferenciación de niveles se hizo atendiendo a criterios sedimentológicos: color, compacidad, estructura y componentes del depósito. Los elementos recuperados se referenciaron mediante coordenadas. La criba se hizo en dos fases, primero en seco y posteriormente en agua, aprovechando la infraestructura para el flotado del sedimento, que permitió recoger todos los restos orgánicos, básicamente carbones dispersos en la matriz terrosa.
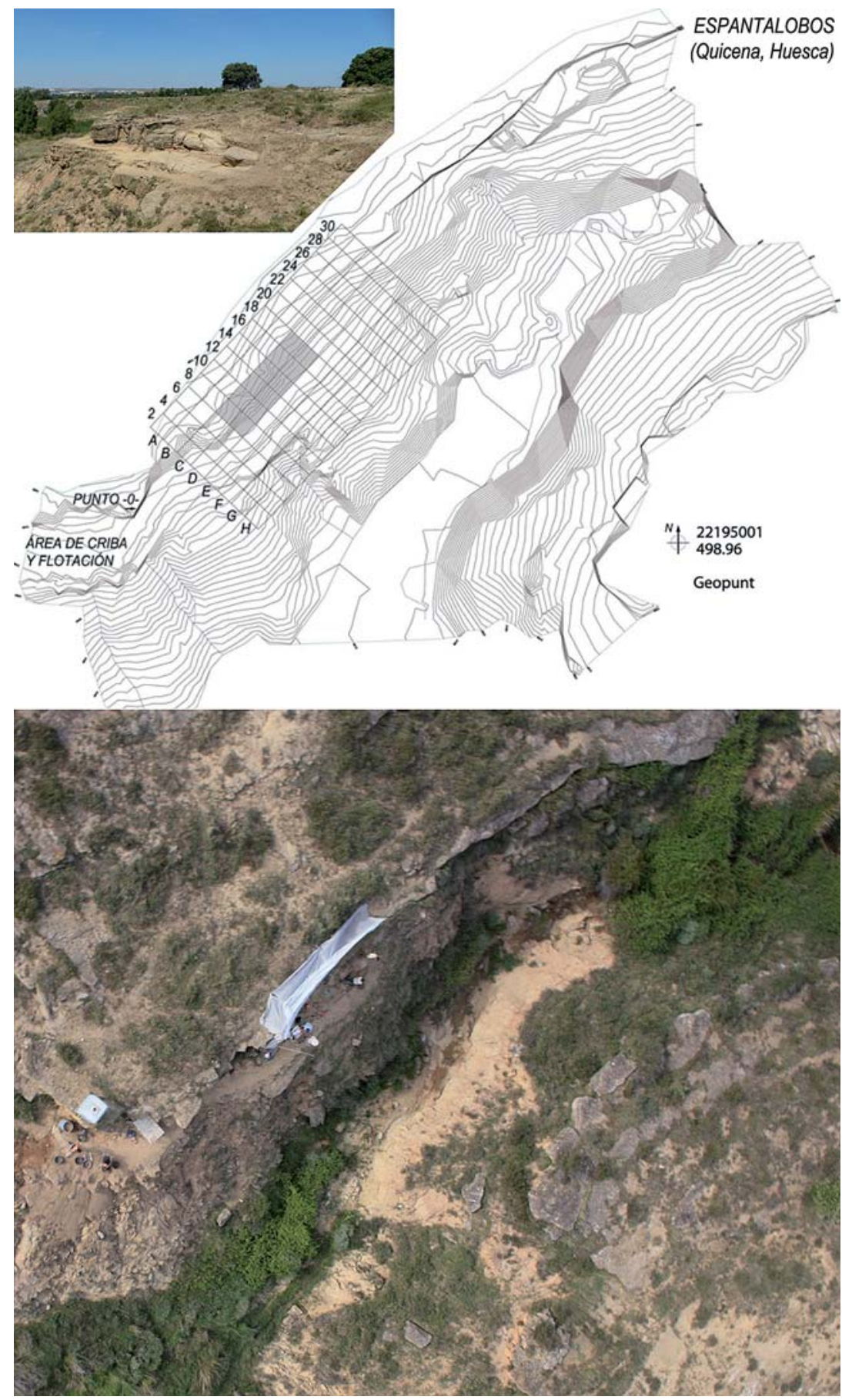

Fig. 2. Topografía (R. Larma) y vista aérea (F. Navajas) del barranco y sitio de Espantalobos (en gris los cuadros excavados en 2013). Esquina superior izquierda: el yacimiento acabada la campaña / Topography (R. Larma) and aerial view (F. Navajas) of the site of Espantalobos and the ravine (grey, excavated surface in 2013). Top left, the site after the 2013 fieldworks. 


\section{3.- EL MARCO GEOLÓGICO Y SEDIMENTOLÓ- GICO: LA ESTRATIGRAFÍA Y SU DATACIÓN}

Geológicamente, a gran escala, el yacimiento de Espantalobos se encuentra ubicado en el límite norte del Mioceno continental de la Cuenca del Ebro. El entorno está conformado por estratos subhorizontales de arenisca y arcilla, de espesor métrico a decamétrico, que se engloban en la Fm. Uncastillo, también conocida como Fm. Sariñena. Las areniscas forman paleocanales con base erosiva en las arcillas, que pueden mostrar laminaciones internas oblicuas y variaciones en la textura, incluyendo gravas de pequeñas dimensiones. Genéticamente, la zona de estudio está situada en la periferia occidental del abanico aluvial denominado Huesca, cuyo ápice estaba situado en la zona de Alquézar y a donde confluían diversos cauces pirenaicos hoy desaparecidos. Entre este abanico y el de Biel, que llegaba hasta Ayerbe, se ha formado la depresión arcillosa de la Sotonera.

A escala media, la zona se localiza al pie del escarpe de Montearagón, que presenta un desnivel próximo al centenar de metros y es un elemento importante en el paisaje de Somontano entre Igriés y Sariñena. En la zona de Montearagón, el escarpe ha sido sometido a una intensa actividad antrópica, por pastoreo, recogida de leñas y, sobre todo, extracción de piedra como se ha dicho. En las inmediaciones del yacimiento, al pie del escarpe, hay un escalón estructural de una anchura media de unos 100 metros que hacia el sur limita con otro pequeño escarpe de unos 10 metros de altura que linda con la zona regada por la acequia de Quicena. El área norte inmediata al yacimiento, conocida como Canteras de Quicena, ha sido intensamente canteada, como se ha dicho, en un amplio periodo que podría abarcar entre el periodo romano e inicios del siglo XX. De hecho, en las cercanías se encuentran marcas para cuñas, superficies con huellas de pico, cicatrices de arranque de bloques e incluso un orificio de barra manual o taladro a rotación.

El yacimiento se encuentra en el tramo superior de la orilla derecha de un pequeño y corto barranco que abre a una depresión donde se ha construido una balsa, antes de dar paso a la zona regada. La ladera del barranco, de unos 8 metros, se abre en su mayor parte en materiales del Mioceno, mientras que la ocupación se data en el Holoceno. Se trata básicamente de materiales removilizados de origen local. Como primera aproximación se podría indicar para la época de la ocupación prehistórica un escenario con un barranco de menor profundidad que el actual. En su fondo (nivel f), tras una fase erosiva se depositó una primera capa de arena (nivel e), que revela cierta energía. Es posible que el techo de este depósito se reerosionara parcialmente antes de la acumulación por arroyada local del nivel $d$ suprayacente, que tiene aspecto de un coluvión lateral, sin que pueda descartarse la acción del viento. Sobre esta capa cuya superficie muestra evidentes signos de erosión, se desarrolla la segunda ocupación humana (nivel c). El desmantelamiento de un cortado suprayacente y una probable visera deslizaban periódicamente, por descalzamiento, bloques de arenisca de tamaño variable. En cualquier caso, es difícil analizar el depósito en su entorno natural dada la importante modificación del paisaje en épocas más recientes por efecto de la extracción de roca.

La intervención no arrancó en la parte superior de la ladera, sino en el escalón en el que se advertía una capa cenicienta a la que se denominó nivel c, reservando las letras a y b para otras capas que pudieran aparecer por encima al remontar el desnivel con los trabajos. Esta es la secuencia observada (Figura 3):

- nivel superficial: capa estéril de coloración clara, cuyo grosor varía según la pendiente de la ladera: mas gruesa en las áreas con menos pendiente que acumulan derrubios, y apenas perceptible en las zonas muy empinadas donde la erosión impide su acopio;

- nivel c: arqueológicamente fértil, está formado por una matriz arenosa con algunas arcillas, de color ceniciento y con multitud de carboncillos y pequeños fragmentos de roca arenisca, muchos de ellos alterados por fuego, dispersos. En su seno se localizaron restos líticos y también de fauna, además de algunas estructuras de combustión (hogares) responsables del aporte de cenizas y carbones. Además de los aportes antrópicos, su formación arenosa-arcillosa parece ser mixta, a partir de aportes eólicos, gravitacionales (derrubios de ladera) y por la descomposición del banco de arenisca, del que proceden también los pequeños clastos de arenisca;

- nivel d: es una capa estéril de color beige amarillento claro, cuya matriz arcillosa es mucho más compacta que el nivel c. El predominio de las arcillas y su estructura masiva se debería a su formación, que parece principalmente ligada a fenómenos de arroyada difusos y/o a la alteración de las arcillas miocenas del nivel $f$, al que se superpone directamente en algunas zonas (banda 10);

- nivel e: localizado por debajo del nivel d sólo en los cuadros 12D-16D, se diferencia de este por la presencia de carboncitos dispersos y en su matriz arenosa, ligeramente cenicienta. Dispuesto en forma de cubeta, su sedimentación parece relacionada en algún modo con un medio acuático. Muy afectado por la erosión, la superficie excavada en 2013 es muy inferior a la del nivel c. En su interior se localizaron algunos restos líticos y óseos;

- nivel f: corresponde a las arcillas miocenas que sirven de base al paleocanal de arenisca, y que en la zona reciben el nombre de salagón. En origen son arcillas que muestran una alternancia de colores rojos, grises y pardos, masivas y poco permeables, cuya superficie erosionan con facilidad las escorrentías de agua, formando regueros y cárcavas. Es difícil distinguir un depósito original de otro alterado (sea por causas humanas o naturales). Lateralmente este nivel $f$ de arcillas alterna con margas arcillosas, también de origen mioceno. La aparición de cualquiera de estas dos variantes indica el final de la secuencia arqueológica. 

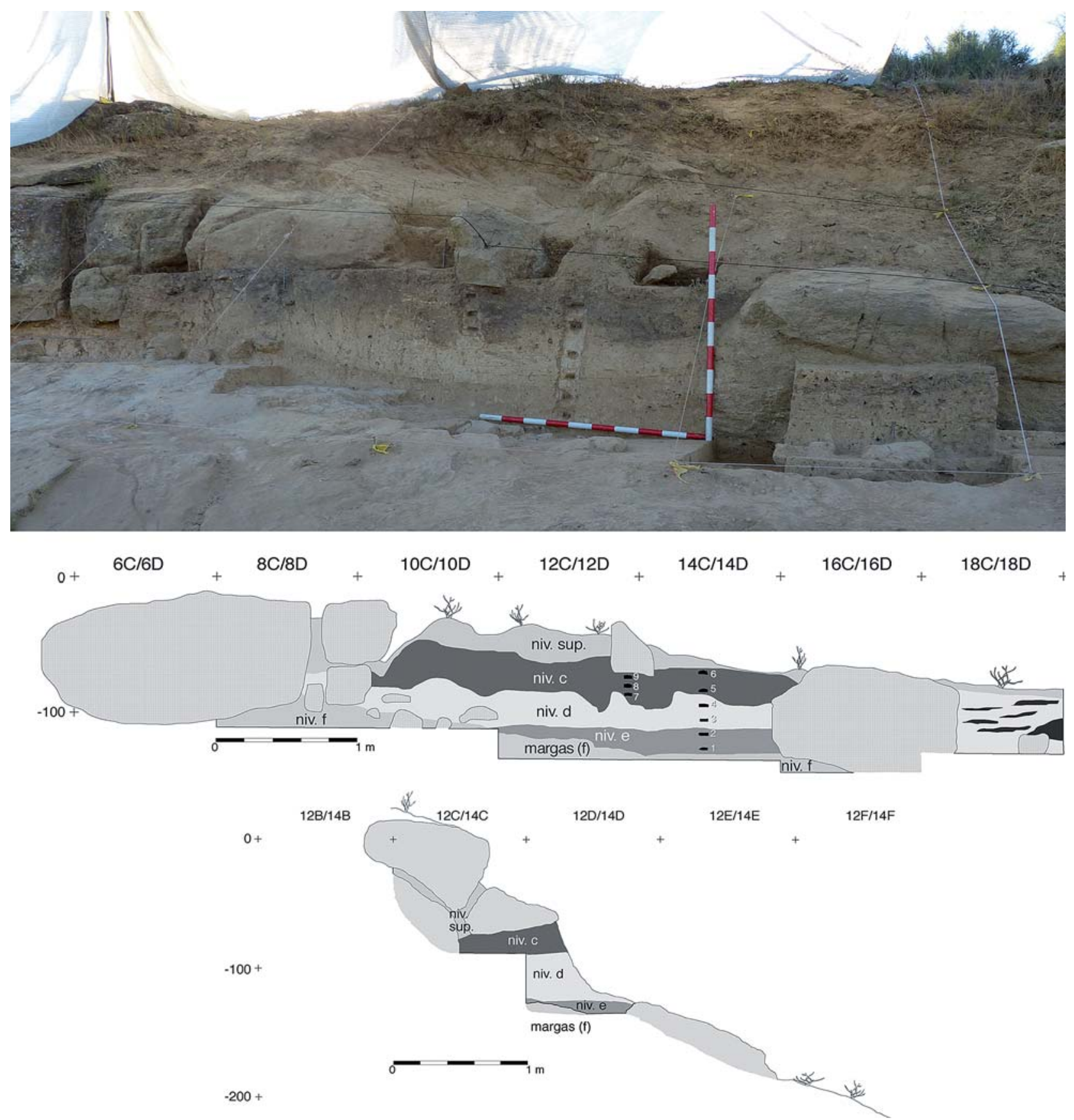

Fig. 3. Cortes estratigráficos: arriba, longitudinal entre las bandas C/D (fotografía y dibujo); debajo, transversal entre las bandas $12 / 14$ / Stratigraphic sections: top, longitudinal between C/D bands (photography and drawing); below, cross section between 12/14 bands.

Es habitual que las intervenciones en abrigos de este tipo muestren problemas respecto a la conservación del sedimento. Lo que ya no es tan normal es que dichos problemas afecten de forma severa al banco de piedra que acoge al yacimiento, alterado profundamente en este caso por las mencionadas tareas de cantería además de por los habituales procesos erosivos.

La datación de las dos capas arqueológicas se intentó en un primer momento con muestras óseas seleccionadas en un mismo cuadro y enviadas a Beta
Analytic: su nulo contenido en colágeno impidió obtener resultados. Por ello hubo que enviar a datar algunos de los carbones recuperados, para lo que se seleccionaron dos muestras en función de su fiabilidad y representatividad respecto del depósito (Tabla 1). En ambos casos se trataba de un único carbón de Juniperus sp. procedentes del mismo cuadro (14D) y sector (8): el del nivel c se obtuvo en un hogar claramente delimitado ( $z$ : 95); el del nivel e se individualizó dentro del sector en la semitalla $125-130$ 


\begin{tabular}{|c|c|c|c|c|c|}
\hline NIVEL & $\boldsymbol{z}$ & Muestra & $\begin{array}{c}\text { Referencia } \\
\text { Laboratorio }\end{array}$ & Fecha BP & $\begin{array}{c}\text { Fecha } \\
\text { CAL BP (2 } \boldsymbol{\sigma})\end{array}$ \\
\hline Nivel c & -95 & Juniperus sp. & Beta-361624 & $7390 \pm 40$ & $8321-8046$ \\
\hline Nivel e & -130 & Juniperus sp. & Beta-361625 & $7900 \pm 50$ & $8975-8547$ \\
\hline
\end{tabular}

Tabla 1: Espantalobos: fechas C14 y su calibración (OXCAL v4.2.4) / Espantalobos: BP and calibrated C14 dates (OXCAL v4.2.4).

\subsection{El acondicionamiento del emplazamiento: las estructuras conservadas}

Se han identificado algunas estructuras de combustión, todas ellas pertenecientes al nivel $c$. Estos hogares aparecen formados por amontonamientos de clastos de arenisca y cantos rodados de caliza que fueron aportados voluntariamente hasta el sitio, desde los restos del antiguo glacis que corona el saso de Montearagón o desde el vecino cauce del Flumen. El mejor conservado es una estructura circular muy simple, formada por un amontonamiento de clastos de arenisca y cantos que contenía una importante concentración de carbones, entre ellos el enviado a datar. En otras ocasiones, la presencia de hogares en cubeta, sin piedras perimetrales, queda evidenciada simplemente en el sedimento rubefactado de la solera de la depresión: una franja de tierra de color rojizo intenso sobre la que aparece el depósito negruzco resultante de la acumulación de carbones y cenizas. La fuerte alteración térmica de algunas areniscas parece indicar que adosadas a ellas se produjo una combustión de cierta intensidad y duración, presumiblemente en unos hogares cuyas estructuras ya habían sido

\begin{tabular}{|l|c|c|c|c|c|c|}
\hline \multirow{2}{*}{ NIVEL } & \multicolumn{3}{|c|}{ Industria lítica } & \multirow{2}{*}{ Fauna } & \multirow{2}{*}{ Otros } & TOTAL \\
\cline { 2 - 7 } & Sílex & Otros & Total & & & \\
\hline Revuelto & 90 & 10 & 100 & 4 & - & 104 \\
\hline Nivel c & 296 & 72 & 368 & 60 & 2 (Goethita y Yunque) & 430 \\
\hline Nivel e & 131 & 15 & 146 & 49 & 1 (Columbella) & 196 \\
\hline TOTAL & $\mathbf{5 1 7}$ & $\mathbf{9 7}$ & $\mathbf{6 1 4}$ & $\mathbf{1 1 3}$ & $\mathbf{3}$ & $\mathbf{7 3 0}$ \\
\hline
\end{tabular}

Tabla 2: Espantalobos: distribución de restos por materias y niveles / Espantalobos: archaeological remains by type and level. totalmente desmanteladas (quizás en tiempos prehistóricos) cuando se realizó la excavación.

Dada la superficie excavada del nivel $c$, la presencia de al menos tres estructuras de combustión identificadas y de otras tres supuestas a partir de las rocas rubefactadas, supone un elevado número de hogares. La diferencia de cotas y la relativa proximidad entre estos hogares podría deberse a la recurrencia de las visitas al lugar, en momentos (incluso en años) diferentes.

\section{4.- LOS MATERIALES ARQUEOLÓGICOS Y OTROS RESTOS}

La campaña de 2013 proporcionó restos significativos aunque no muy numerosos. La superficie excavada fue reducida, especialmente en el nivel e, porque la zona en la que se trabajó era el límite de la ocupación y porque la erosión de la banda D y las grandes rocas del fondo limitan la extensión de la banda C. Una vez terminados los inventarios, el total de restos registrados asciende a 730 (Tabla 2). La diferencia de número de restos entre los niveles c y erefleja la diferencia entre las áreas excavadas en cada uno.

\subsection{La industria lítica}

En ambos niveles y sin que de momento se hayan registrado diferencias formales significativas, el tipo de industria es el mismo y comparte dos producciones diferenciadas pero complementarias entre sí (Tabla 3). La primera en sílex, de base laminar y tamaño reducido cuyos materiales más significativos son las armaduras geométricas; la segunda, sobre rocas locales, mayoritariamente calizas pero también alguna arenisca, cuarcita..., de las que se obtienen lascas que después casi no se retocan y como elementos más significativos algunos instrumentos de gran tamaño (chopper, rabot) realizados directamente sobre cantos. En números absolutos el sílex supone algo más del $84 \%$ del total, mientras que calizas y similares apenas alcanzan el $16 \%$. Aunque la distribución por niveles ofrece ciertas diferencias (sílex:

\begin{tabular}{|c|c|c|c|c|c|c|c|c|c|}
\hline & \multicolumn{2}{|c|}{ REVUELTO } & \multicolumn{2}{|c|}{ NIVEL $c$} & \multicolumn{2}{|c|}{ NIVEL e } & \multirow{2}{*}{ TOTAL } & \multirow{2}{*}{ Total Sílex } & \multirow{2}{*}{ Total Otros } \\
\hline & Sílex 90 & Otros 10 & Sílex 296 & Otros 72 & Sílex 131 & Otros 15 & & & \\
\hline Lasca & - & 5 & 3 & 23 & 3 & 9 & 43 & 6 & 37 \\
\hline Lasquita & 22 & - & 48 & - & 27 & - & 97 & 97 & - \\
\hline Microlasca talla & 21 & - & 81 & - & 43 & - & 145 & 145 & - \\
\hline Lámina & 0 & - & 15 & - & 5 & - & 20 & 20 & - \\
\hline Laminita & 29 & - & 84 & - & 28 & - & 141 & 101 & - \\
\hline Chunk/Débris & 17 & 5 & 64 & 47 & 24 & 5 & 166 & 105 & 57 \\
\hline Avivado & 1 & - & - & - & 1 & - & 2 & 2 & - \\
\hline Núcleo & - & - & 1 & - & - & - & 1 & 1 & - \\
\hline Canto Tallado & - & - & - & 2 & - & 1 & 3 & - & 3 \\
\hline TOTAL & \multicolumn{2}{|c|}{100} & \multicolumn{2}{|c|}{368} & \multicolumn{2}{|c|}{146} & 614 & 517 & 97 \\
\hline
\end{tabular}

Tabla 3: Espantalobos: industria lítica por nivel, materia y soporte (incluidos retocados) / Espantalobos: lithic remains by raw material and support type (included retouched tools) 
$80,4 \%$ en nivel c y $89,7 \%$ en el nivel e), dado lo provisional de los datos ofrecidos no parece conveniente detenerse en analizar estas cifras.

La base tecnológica de la industria sobre sílex se refleja tanto en el evidente formato de los soportes laminares, como en la proporción de éstos sobre todo el recuento: en el nivel c, un total de 99 láminas/laminitas (o fragmentos de ellas) sobre 296 registros de sílex implican un 33,4\%; los 33 casos del nivel e suponen el 25\% de los 131 sílex recuperados. Si se computan sólo los soportes estrictos (láminas y lascas de todos los tamaños, pero no las microlascas de talla que no son buscadas como tales) la proporción duplica la obtenida sobre la totalidad de restos de sílex: es del $66 \%$ en el nivel c y del $52,4 \%$ en el nivel e. Un solitario núcleo de laminitas recuperado en el nivel $c$ completa el conjunto (Figura 4).
A tenor de los restos de sílex recuperados, las labores de talla en el yacimiento fueron las mínimas y de carácter perentorio: parecen responder a la necesidad de reponer el material necesario en un momento dado (geométricos, cuchillos...), lo que se refleja en el bajo número de restos y la anecdótica presencia de núcleos, láminas de cresta y otros productos de avivado, como tabletas y flancos, habituales en los sitios de trabajo intenso del sílex. Los restos sugieren un aporte de escasos núcleos ya testados y preconfigurados, a partir de los cuales se obtuvo casi todo el material registrado: los microburiles indican la fabricación in situ de algunas armaduras geométricas a partir de los soportes laminares y el núcleo del nivel c, aparecido junto con una lámina reflejada que remonta, permite rastrear esta baja actividad de talla. Prácticamente todos los sílex recuperados parecen ser de la variedad "Monegros":
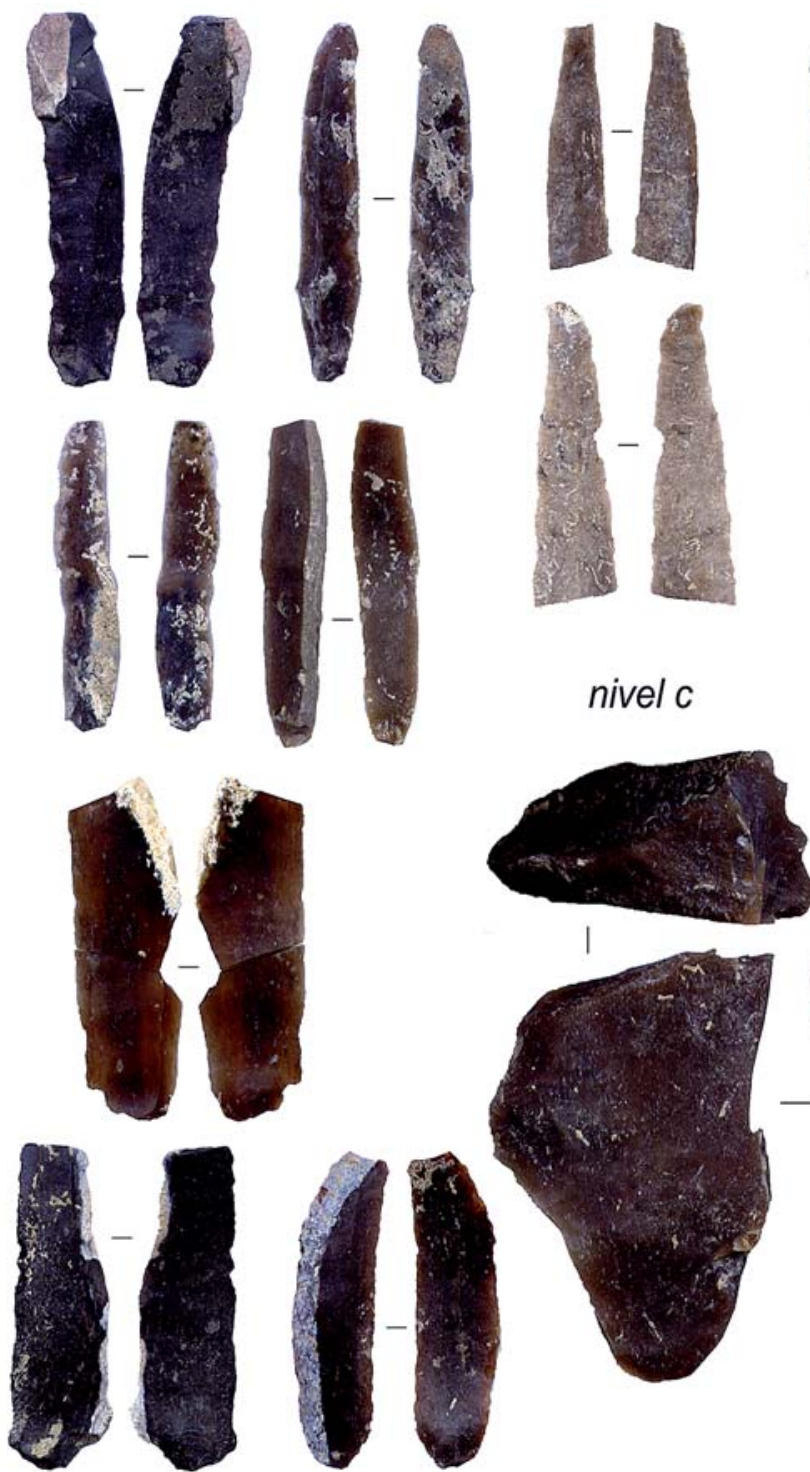

(1)

nivel c
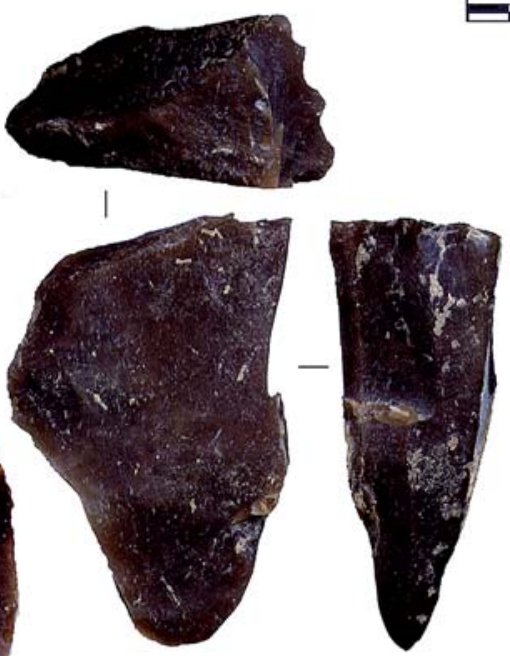
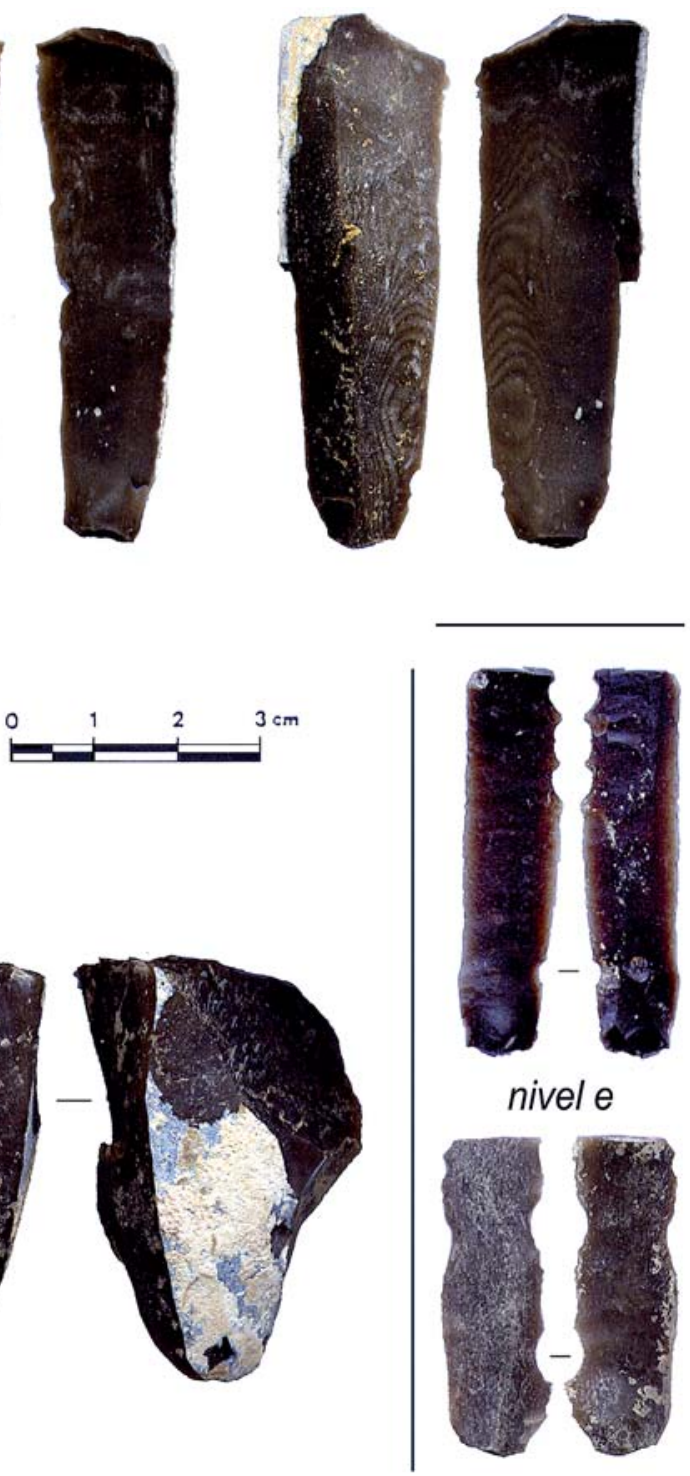

nivel e

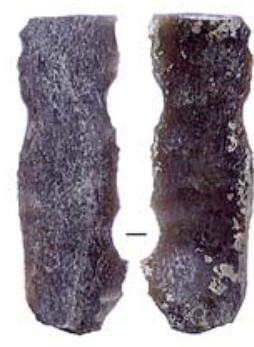

Fig. 4. Soportes laminares y núcleo de láminas de los niveles c y e. Las dos láminas mayores de la parte superior derecha remontan entre sí / Bladelet core and blades from levels $\mathrm{c}$ and $\mathrm{e}$. The two major blades at the upper right refit. 
excelentes para la talla, de grano y córtex muy finos, y tonalidades marrones (GARCÍA-SIMÓN y MANDADO, 2014). Entre ellos, destacan dos láminas mayores, que remontan entre sí, con el córtex algo más grueso y con los característicos anillos de Liesegang. Sin poder precisar todavía su origen exacto, se puede citar la presencia de nódulos de este tipo en las proximidades de Tardienta y Torralba de Aragón, a unos $30 \mathrm{~km}$ al suroeste de Espantalobos como punto más próximo conocido. Los nódulos aparecen en las calizas de la formación 9 (arcillas y margas varioladas con capas de areniscas y calizas, Aragoniense) de la Unidad Monte de Pallaruelo/Sierra de la Sora (IGME, Mapa geológico de España 1:50.000, hoja 323, Zuera). En prospecciones realizadas en la zona se han recogido algunos de estos nódulos, cuyos caracteres macroscópicos son prácticamente idénticos a los del yacimiento.

En calizas y demás tipos de rocas no silíceas, las lascas son los únicos soportes obtenidos y a ellas se suma un buen número de fragmentos amorfos (chunks/débris) producidos por la fractura no concoidea de este tipo de rocas, y tres cantos transformados directamente en instrumentos de carácter masivo y gran tamaño. Las lascas realizadas sobre estas litologías, mayoritariamente calizas, aparecen sin retocar y pudieron usarse en algunos casos como cuchillos de filo natural -mas tenaces aunque menos cortantes que los de sílex- que habrían servido para trabajar materias más duras. Las 3 piezas reconocidas están realizadas directamente sobre cantos de caliza: 2 choppers o cantos tallados unifacialmente, uno en cada nivel, y un posible rabot o cepillo en el nivel $c$ c. Estas piezas se pueden relacionar tanto con el trabajo de la madera y vegetales en general, como con el despiece inicial de las presas cazadas y con el procesado de sus carcasas. Estos materiales parecen proceder del Saso de Montearagón, que sobremonta inmediatamente la zona de Espantalobos, y que geológicamente se corresponde con el resto de un antiguo nivel de glacis o terraza. Los cantos pudieron ser recogidos directamente en la plataforma conservada (saso) o en las inmediaciones del asentamiento a donde llegan por caída.

Las piezas retocadas presentan también diferencias en función de la litología de sus soportes (Tabla 4 y Figura 5): si en caliza hay cantos trabajados, en sílex lo más característico son las armaduras geométricas (4 en el revuelto, 7 en el nivel c y 2 en el nivel e), entre las que predominan los trapecios asimétricos de retoque abrupto, estilizados y apuntados, con uno (G5) o dos lados cóncavos (G6) según la tipología de FORTEA (1973). En el revuelto apareció un trapecio de lado convexo (G7). Los geométricos fueron obtenidos mediante la técnica del microburil (M1), desechos de los que se han computado 11 ejemplares en el nivel $c$ (distales y proximales) y otro distal en el revuelto. Otro grupo importante son las lascas y láminas con muescas y denticuladas: 15 ejemplares que se distribuyen a razón de 2 en el revuelto, 4 en el nivel c y 9 en el nivel e. Algunas de las láminas con muesca (MD3) y denticuladas (MD4) pueden estar relacionadas con la técnica de obtención de los geométricos y en ese sentido, su distribución por niveles no ofrece datos llamativos. Es interesante la distribución de las lascas denticuladas (MD2): 3 ejemplares limitados exclusivamente al nivel e, una de ellas con el retoque inverso y dimensiones superiores a la media. Si a ello se une una mayor proporción de lascas en este nivel y quizás un cierto "aire" distinto en los dos únicos geométricos localizados, el conjunto evoca en parte al Mesolítico de Muescas y Denticulados, que casaría también con la fecha obtenida: en la cuenca del Ebro, circa 870 cal BP es una data puente entre los conjuntos de Muescas y Denticulados y los Mesolíticos Geométricos más antiguos (ALDAY y CAVA, 2006 y 2009; MONTES et al. 2006; UTRILLA et al., 2009).

\begin{tabular}{|l|c|c|c|c|c|c|}
\hline & REVUELTO & NIVEL $c$ & NIVEL $e$ & TOTAL & Sílex & Otros \\
\hline Iba 11 & - & 1 & - & 1 & 1 & - \\
\hline MD1 & - & 1 & - & 1 & 1 & - \\
\hline MD2 & - & - & 3 & 3 & 3 & - \\
\hline MD3 & - & 1 & 2 & 3 & 3 & - \\
\hline MD4 & 2 & 2 & 4 & 8 & 8 & - \\
\hline FR1 & - & 1 & - & 1 & 1 & - \\
\hline G2 & - & - & 1 & 1 & 1 & - \\
\hline G5 & 3 & 5 & - & 8 & 8 & - \\
\hline G6 & - & 2 & 1 & 3 & 3 & - \\
\hline G7 & 1 & - & - & 1 & 1 & - \\
\hline M1 & 1 & 11 & - & 12 & 12 & - \\
\hline D1 & - & 1 & 1 & 2 & 2 & - \\
\hline D2 & - & 5 & 1 & 6 & 6 & - \\
\hline D8 & 1 & - & - & 1 & 1 & - \\
\hline Chopper & - & 1 & 1 & 2 & - & 2 \\
\hline Rabot & - & 1 & - & 1 & - & 1 \\
\hline TOTAL & 8 & 33 & 14 & 55 & 52 & 3 \\
\hline
\end{tabular}

Tabla 4: Espantalobos: piezas retocadas y microburiles / Espantalobos: retouched tools and microburins.

El resto de las piezas tienen una presencia testimonial: un fragmento de laminita de borde abatido (Iba11), una truncadura (FR1), algunas laminitas con retoques liminales (D2) y una pieza esquirlada (D1) completan el registro del nivel c; otra pieza esquirlada (D1) y una lasca con retoques poco definidos (D2) lo hacen en el nivel e.

\subsection{Los elementos de adorno}

Entre el material recuperado hay que citar una Columbella rustica, habitual en estos yacimientos. Apareció en el nivel e, rota (Figura 5): la falta del extremo apical conecta con la habitual perforación que permitía su uso como colgante, también accidentalmente ampliada. Estas transformaciones pudieron producirse con el uso, o generarse en el depósito arqueológico por alteración del mismo: con esta posibilidad se debe relacionar una segunda perforación de dimensiones mínimas y ubicación no habitual, que parece tener un origen natural. Entre los materiales recuperados en la superficie del sitio por su descubridor, I. Gracia, hay otra Columbella rustica intacta, perfectamente conservada. 

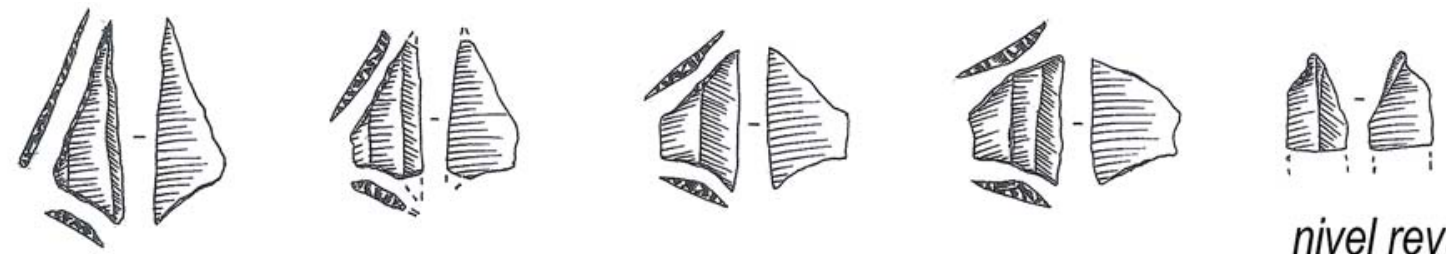

nivel revuelto
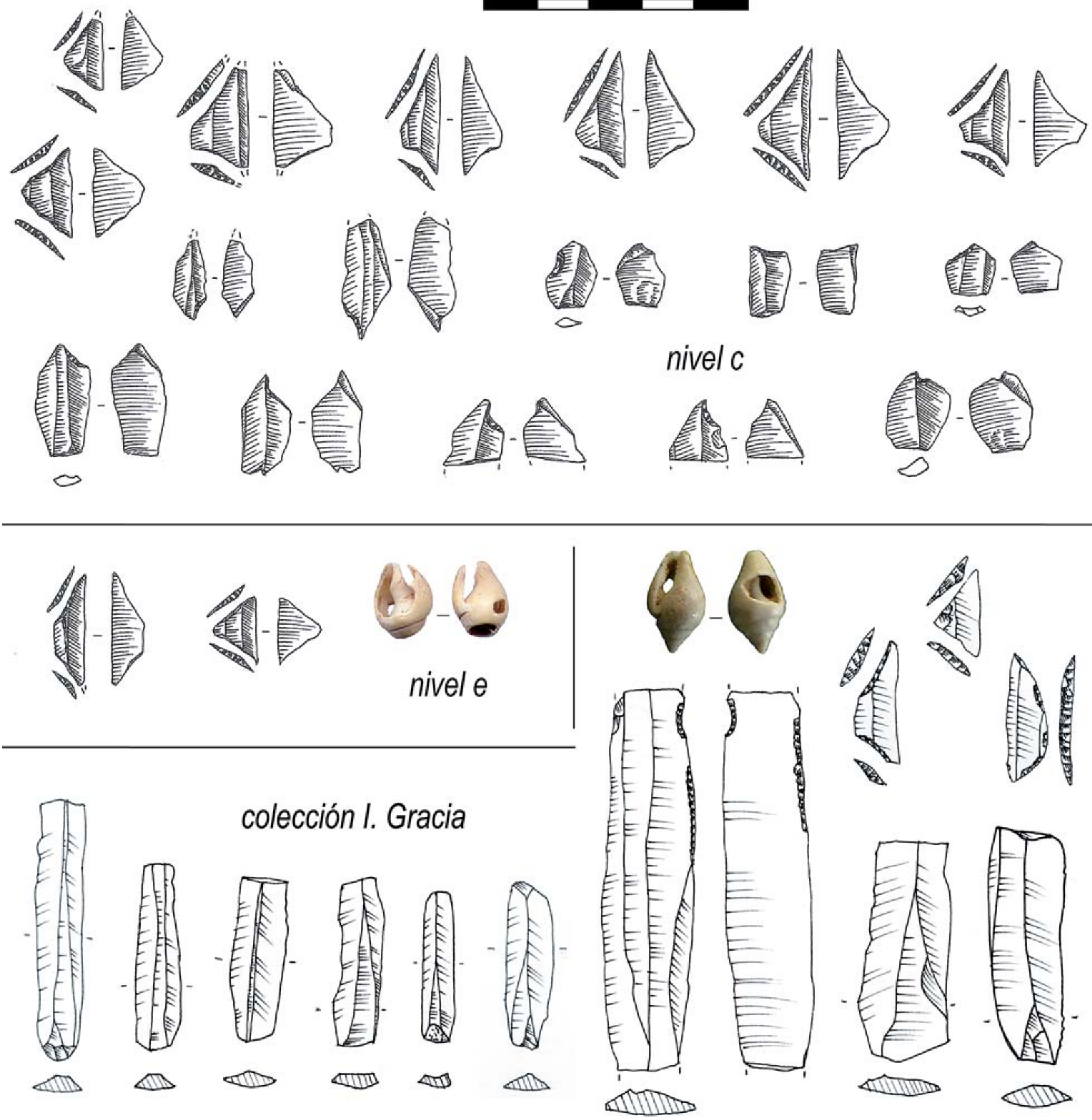

Fig. 5. Espantalobos: microlitos geométricos, microburiles y Columbella rustica de la excavación. Debajo, láminas de sílex, geométricos y Columbella del descubrimiento. (Dibujos de la colección Gracia: P. Sánchez; resto: M.C. Sopena) / Espantalobos: geometric armatures, microburins and Columbella rustica from the excavation. Below, flint blades, geometrics and Columbella from the discovery. (Drawings from Gracia collection: P. Sánchez; others: M.C. Sopena). 


\subsection{La fauna recuperada}

Los vestigios de fauna son poco abundantes: 113 registros (60 en el nivel c, 49 en el nivel e y 4 en el revuelto), y corresponden en 18 casos a huesos o esquirlas individualizados (12 en el nivel $c$, 6 en el nivel e) y en 95 a agrupaciones de esquirlas de pequeño tamaño recuperadas, como los carbones, por sector y semitalla. Algunos huesos individualizados y parte de las esquirlas, por su talla, corresponden a mamíferos de tamaño grande y han sido catalogados como macrofauna indeterminada, al no poder establecer su filiación debido a la alta fragmentación. Sólo han sido susceptibles de identificación anatómica y taxonómica 4 restos de cabra y 2 de ciervo. Cabe destacar la práctica ausencia de piezas dentarias (apenas algún fragmento irreconocible) y como elemento más significativo un candil de cuerna de ciervo, en precario estado de conservación, del nivel e (Tabla 5).

\begin{tabular}{|l|c|c|c|c|}
\hline & REVUELTO & NIVEL c & NIVEL e & TOTAL \\
\hline Capra pyrenaica & - & 3 & 1 & 4 \\
\hline Cervus elaphus & & - & 2 & 2 \\
\hline Indet. macro & 2 & 35 & 22 & 59 \\
\hline $\begin{array}{l}\text { Oryctolagus } \\
\text { cuniculus }\end{array}$ & 2 & 20 & 21 & 43 \\
\hline Microfauna & - & 2 & 3 & 5 \\
\hline TOTAL & $\mathbf{4}$ & $\mathbf{6 0}$ & $\mathbf{4 9}$ & $\mathbf{1 1 3}$ \\
\hline
\end{tabular}

Tabla 5: Espantalobos: restos de fauna por nivel / Espantalobos: faunal remains by level.

La alta fragmentación de los restos ha dificultado también el análisis tafonómico de los mismos. Sin embargo, se ha detectado una marca de corte antrópica en un fragmento de tibia de Capra pyrenaica del nivel c. Los otros 2 restos de cabra de este nivel, un hueso largo de ciervo del nivel e, el $40 \%$ de los restos de conejo y el $37 \%$ de las esquirlas de macrofauna de ambos niveles muestran indicios de haber sido sometidos a la acción del fuego. Se han detectado todos los estadios posibles de cremación, presentando la mayoría de los restos coloraciones marrones y negras, que implican que no fueron sometidos al fuego durante largos períodos de tiempo o de forma directa. Estas alteraciones y la marca de corte evidencian un aprovechamiento cárnico de la fauna encontrada en el yacimiento de Espantalobos, destacando la buena representación del conejo en ambos niveles arqueológicos, que permite considerarlo como una presa permanente. Además de los procesos tafonómicos de origen antrópico, se han detectado otros de carácter natural como procesos de tinción, provocado por óxidos ferrosos y la presencia de manganeso en los sedimentos, marcas de dientes realizadas por roedores, y un ejemplo de marcas realizadas por raíces.

\subsection{Los macrorrestos vegetales}

Durante la excavación se recogieron manualmente todos los restos vegetales carbonizados por sector y semitalla $(33 \times 33 \times 5 \mathrm{~cm})$ debidamente etiquetados y almacenados en recipientes rígidos para evitar la sobrefragmentación.
En lo que respecta al procesado del sedimento, se combinó el tamizado en seco y la flotación manual con tamices de $2 \mathrm{~mm}$ de luz de malla para garantizar una recogida integral de este tipo de restos. De esta forma se procesó la totalidad del sedimento excavado recuperándose un total de 137 registros individualizados por sector y semitalla (82 del nivel c y 55 del nivel e) compuestos por un número variable de macrorrestos dispersos por la superficie del yacimiento. Asímismo se cuenta con 3 muestras individuales procedentes del nivel c (referenciadas mediante las 3 coordenadas) correspondientes a carbones procedentes del interior de dos hogares (en 10D y en 14D). En lo que respecta a los restos antracológicos, aunque los fragmentos de carbón recuperados son por lo general de pequeño tamaño (entre 5 y $2 \mathrm{~mm}$ ) como es habitual en yacimientos de estas cronologías, son abundantes y se encuentran en buen estado de conservación, lo que hace posible su identificación botánica en la mayoría de los casos.

Los resultados de los análisis antracológicos obtenidos sobre una muestra parcial de 200 fragmentos de carbón disperso en el sedimento (100 por nivel, procedentes de 4 registros del nivel c y 6 del nivele, todos del cuadro 14D) ha permitido la determinación de 11 taxones diferentes (Tabla 6). A pesar de haber procesado la totalidad del sedimento excavado, la frecuencia de aparición de restos carpológicos fue muy baja y de momento sin resultados. Entre la flora sedimentada destaca la presencia de coníferas, representadas por pino carrasco (Pinus halepensis) y enebro/sabina (Juniperus sp.). Acompañando a estas especies se documenta una amplia variedad de taxones mesotermófilos como arce (Acer sp.), lentisco (Pistacia sp.), boj (Buxus sempervirens) y prunoideas (Prunus sp). Muy bien representados aparecen también los matorrales de tipo heliófilo entre los que destacan el romero (Rosmarinus officinalis) y algunas plantas de la familia de las leguminosas (Leguminosae). Estas últimas son además consideradas especies de ignición, empleadas con frecuencia para iniciar el proceso de combustión en los hogares. La vegetación riparia aparece representada únicamente por la presencia de un taxón (Salix/Populus). En suma, los resultados preliminares del estudio antracológico revelan el aprovechamiento forestal de un entorno abierto que no desentona en el paisaje mosaico que evidencian las secuencias palinológicas (GONZÁLEZ-SAMPÉRIZ et al., 2005; VALERO-GARCÉS et al., 2004) del noreste peninsular para esta etapa.

\begin{tabular}{|c|c|c|c|}
\hline & Nivel c & Nivel e & \multirow{13}{*}{$\begin{array}{l}\text { Tabla 6: Espantalobos: } \\
\text { taxones identificados a } \\
\text { partir del análisis antra- } \\
\text { cológico / Espantalobos: } \\
\text { taxa identified in the } \\
\text { anthracological analysis. }\end{array}$} \\
\hline Acer sp. & 3 & 23 & \\
\hline Buxus sempervirens & 1 & - & \\
\hline Juniperus sp. & 21 & 41 & \\
\hline Leguminosae & 6 & 3 & \\
\hline Monocotiledoneae & - & 2 & \\
\hline Pinus halepensis & 66 & 21 & \\
\hline Pistacia sp. & - & 3 & \\
\hline $\begin{array}{l}\text { Prunus sp. } \\
\text { Rhamnus/Phillyrea }\end{array}$ & $\begin{array}{l}1 \\
-\end{array}$ & $\overline{4}$ & \\
\hline Rosmarinus officinalis & - & 1 & \\
\hline Salix/Populus & - & 2 & \\
\hline Corteza & 2 & - & \\
\hline TOTAL & 100 & 100 & \\
\hline
\end{tabular}




\section{5.- LA INTERPRETACIÓN DEL YACIMIENTO}

La adscripción cronológica de Espantalobos a partir de las fechas expuestas (Tabla 7) y de sus materiales arqueológicos inserta este enclave en el conjunto del Mesolítico de la cuenca del Ebro (Figuras 6 y 7), que en este territorio presenta dos etapas sucesivas relativamente bien conocidas: comienza con el Mesolítico de Muescas y Denticulados, cuyos conjuntos industriales se desarrollan a lo largo del $X$ milenio y buena parte del IX cal BP. Inmediatamente después, el Mesolítico Geométrico viene a durar grosso modo algo más de un milenio, hasta el 7500 cal BP: tras haber arrancado tempranamente en torno al 9000 cal BP en algunos sitios de la orilla derecha del Ebro (Ángel 1 en el Guadalope, Baños de Ariño en el Martín) su generalización en el resto de la cuenca es algo posterior (ALDAY y CAVA, 2006 y 2009; ALDAY et al. 2014; MONTES et al. 2006; UTRILLA et al. 2009). El final del Mesolítico lo anuncia la presencia pionera de algunas cerámicas en el abrigo de Mendandia (Treviño) y poco después en Forcas-II (Graus) en torno al 8000 y 7800 cal BP respectivamente, siendo comunes a partir del 7600 los materiales neolíticos en los registros arqueológicos

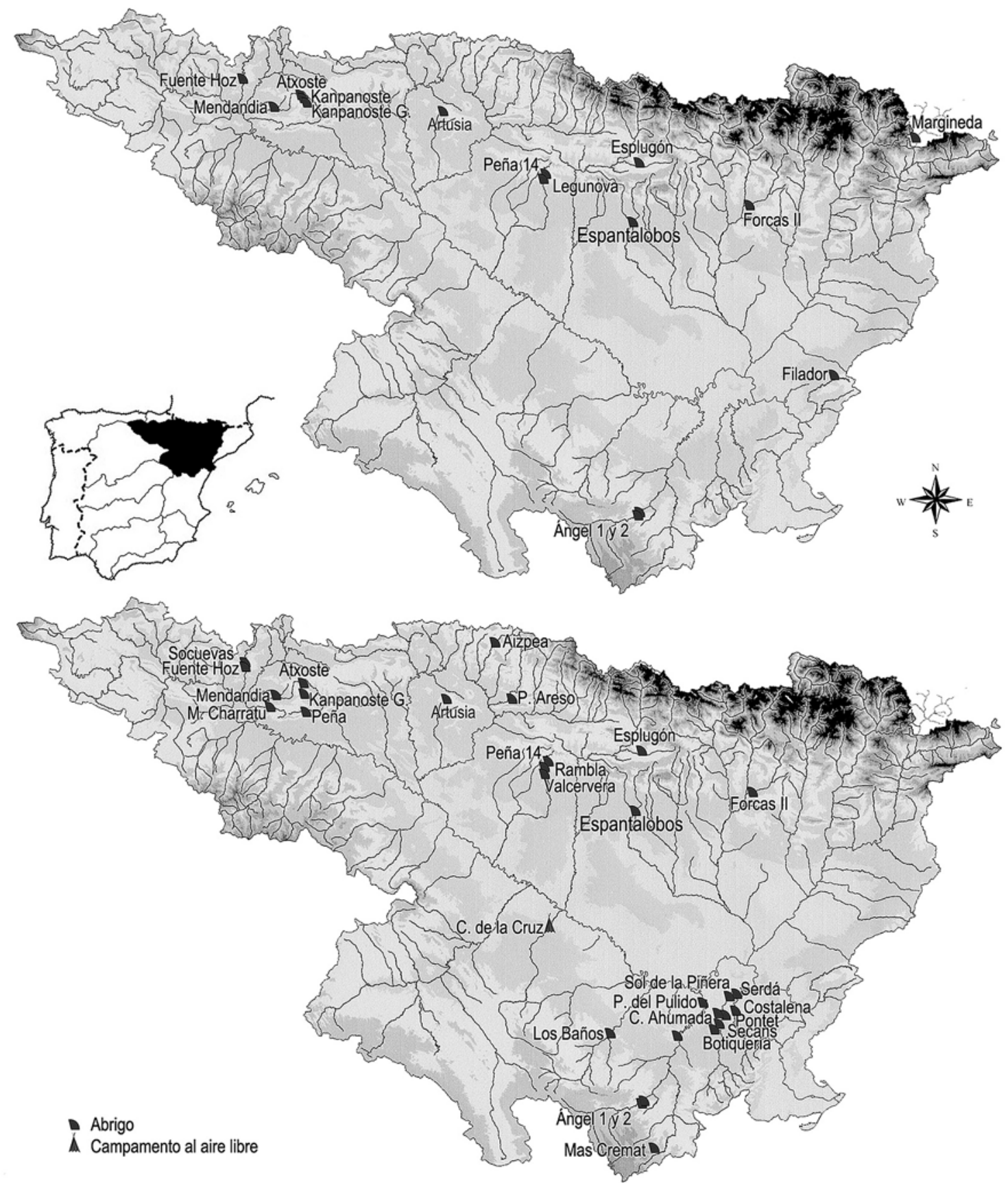

Fig. 6. Asentamientos del Mesolítico de Muescas y Denticulados (arriba) y Geométrico (abajo) en la Cuenca del Ebro / Denticulate (above) and Geometric (below) Mesolithic settlements in the Ebro Basin. 
de la cuenca (ALDAY et al. 2012; MONTES y ALDAY, 2012). Los mapas de la Figura 6 recogen todos los yacimientos mesolíticos excavados de la Cuenca del Ebro, datados o no. Pero la Tabla 7 y la Figura 7 con las curvas resultantes recogen sólo las fechas de los asentamientos de la margen izquierda con desviaciones inferiores a 100.

La más reciente de las dos capas identificadas en Espantalobos, el nivel $c$, se relaciona indudablemente por material y cronología (Figuras 5 y 7 ) con la fase geométrica. Pero la asignación del nivel e plantea ciertos problemas: si se relacionara con el Mesolítico Geométrico, Espantalobos confirmaría la rápida expansión del geometrismo también en la margen izquierda del Ebro, refrendando así la fecha obtenida en el nivel a de Peña-14 en el Arba de Biel (8400 cal BP) (MONTES, 2002). Esta datación del nivel e es tan antigua como las obtenidas en algunos conjuntos geométricos de la margen derecha, como los niveles $2 b 1$ de los Baños de Ariño (8500 cal BP) y 8c de Ángel-1 (8800 cal BP), e incluso en algunos de la orilla izquierda -no seleccionadas por sus desviaciones superiores a 100-, como Peña de Marañón nivel d (7890 \pm 120$)$ o Fuente Hoz nivel III, capa 23 ( $7880 \pm 120$, también datada en $7140 \pm 120)$. Pero todas ellas son fechas muy próximas también a las más recientes del complejo de Muescas y Denticulados (ALDAY et al. 2014), pudiendo servir de bisagra entre ambas fases (Tabla $7 \mathrm{y}$ Figura 7): el poco explícito material recuperado en Espantalobos, apenas un par de geométricos y algunas lascas toscamente denticuladas, no permiten de momento escoger definitivamente una u otra opción hasta ampliar la superficie excavada y conseguir más restos y mejor definidos.

\begin{tabular}{|c|c|c|c|c|c|c|}
\hline YACIMIENTO & NIVEL & FASE & MUESTRA & $\begin{array}{c}\text { REFERENCIA } \\
\text { LABORATORIO }\end{array}$ & $\begin{array}{c}F E C H A \\
B P\end{array}$ & $\begin{array}{c}\text { Cal BP 95\% } \\
\text { (OXCAL v4.2.4) }\end{array}$ \\
\hline \multirow[b]{2}{*}{ Mendandia } & IIlinf & $M G$ & $H H$ & GrN-22743 & $7620 \pm 50$ & $8539-8358$ \\
\hline & IV & $M M D$ & $\begin{array}{l}\mathrm{HH} \\
\mathrm{HH}\end{array}$ & $\begin{array}{l}\text { GrN-22745 } \\
\text { GrN-22744 }\end{array}$ & $\begin{array}{l}7780 \pm 40 \\
7810 \pm 50\end{array}$ & $\begin{array}{l}8630-8453 \\
8750-8450\end{array}$ \\
\hline \multirow[b]{2}{*}{ Atxoste } & $\begin{array}{l}\text { IIIb2 } \\
\text { IV } \\
\text { IV }\end{array}$ & $M G$ & $\begin{array}{l}H \\
H \\
H\end{array}$ & $\begin{array}{l}\text { GrA-13415 } \\
\text { GrA-13418 } \\
\text { GrA-13469 }\end{array}$ & $\begin{array}{l}6940 \pm 40 \\
7340 \pm 50 \\
7480 \pm 50\end{array}$ & $\begin{array}{l}7915-7679 \\
8309-8020 \\
8383-8192\end{array}$ \\
\hline & $\begin{array}{l}V \\
V \\
V \\
V I \\
V I \\
D\end{array}$ & $M M D$ & $\begin{array}{l}H \\
H \\
H \\
H \\
H \\
H\end{array}$ & $\begin{array}{l}\text { GrA-13447 } \\
\text { GrA-13472 } \\
\text { GrA-13448 } \\
\text { GrA-15700 } \\
\text { GrA-15699 } \\
\text { GrA-13473 }\end{array}$ & $\begin{array}{l}7810 \pm 40 \\
7830 \pm 50 \\
8030 \pm 50 \\
8510 \pm 80 \\
8760 \pm 50 \\
8840 \pm 50\end{array}$ & $\begin{array}{c}8699-8459 \\
8855-8455 \\
9031-8658 \\
9670-9310 \\
10115-9555 \\
10159-9705\end{array}$ \\
\hline \multirow{2}{*}{ Kanpanoste Goikoa } & IIIsup & $M G$ & $H H$ & GrN-20214 & $6360 \pm 70$ & $7425-7165$ \\
\hline & IIlinf & $M M D$ & $\mathrm{HH}$ & GrN-20215 & $7620 \pm 80$ & $8590-8218$ \\
\hline Kanpanoste & $\begin{array}{l}\text { Lanhi } \\
\text { Lanhs }\end{array}$ & $M M D$ & $\begin{array}{l}\mathrm{HH} \\
\mathrm{HH}\end{array}$ & $\begin{array}{l}\text { GrN-22441 } \\
\text { GrN-22440 }\end{array}$ & $\begin{array}{l}8200 \pm 70 \\
7620 \pm 70\end{array}$ & $\begin{array}{l}9400-9008 \\
8583-8322\end{array}$ \\
\hline \multirow[t]{2}{*}{ Aizpea } & $\begin{array}{l}\text { II } \\
I I \\
l\end{array}$ & $M G$ & $\begin{array}{c}H \\
H H \\
H H\end{array}$ & $\begin{array}{c}\text { GrA-779 } \\
\text { GrN-16622 } \\
\text { GrN-16621 }\end{array}$ & $\begin{array}{l}6600 \pm 50 \\
6830 \pm 70 \\
7160 \pm 70\end{array}$ & $\begin{array}{l}7570-7430 \\
7826-7571 \\
8160-7853\end{array}$ \\
\hline & I & $M M D$ & $\mathrm{HH}$ & GrN-16620 & $7790 \pm 70$ & $8856-8410$ \\
\hline \multirow[b]{2}{*}{ Peña-14 } & $a$ & $M G$ & C & GrN-25094 & $7660 \pm 90$ & $8637-8224$ \\
\hline & $b$ & $M M D$ & $\begin{array}{l}C \\
C\end{array}$ & $\begin{array}{l}\text { GrN-25998 } \\
\text { GrN-25999 }\end{array}$ & $\begin{array}{l}8000 \pm 90 \\
8000 \pm 80\end{array}$ & $\begin{array}{l}9112-8598 \\
9077-8605\end{array}$ \\
\hline Rambla & 2 & $M G$ & $\begin{array}{l}\mathrm{C} \\
\mathrm{H}\end{array}$ & $\begin{array}{l}\text { GrA-47886 } \\
\text { GrA-61768 }\end{array}$ & $\begin{array}{l}7235 \pm 45 \\
7260 \pm 45\end{array}$ & $\begin{array}{l}8164-7970 \\
8174-7983\end{array}$ \\
\hline Legunova & $\begin{array}{l}1 \\
1 \\
2\end{array}$ & $M M D$ & $\begin{array}{l}C \\
C \\
C\end{array}$ & $\begin{array}{l}\text { GrA-24292 } \\
\text { GrA-22086 } \\
\text { GrA-24294 }\end{array}$ & $\begin{array}{l}8200 \pm 50 \\
8250 \pm 60 \\
8800 \pm 60\end{array}$ & $\begin{array}{c}9300-9015 \\
9417-9032 \\
10154-9610\end{array}$ \\
\hline Valcervera & $b$ & $M G$ & $\begin{array}{l}\mathrm{C} \\
\mathrm{H} \\
\mathrm{H}\end{array}$ & $\begin{array}{l}\text { GrA-27876 } \\
\text { GrA-45783 } \\
\text { GrA-45763 }\end{array}$ & $\begin{array}{l}6815 \pm 45 \\
6995 \pm 40 \\
7035 \pm 45\end{array}$ & $\begin{array}{l}7727-7580 \\
7934-7727 \\
7960-7760\end{array}$ \\
\hline \multirow{2}{*}{ Esplugón } & III inf & $M G$ & $\begin{array}{l}H \\
C\end{array}$ & $\begin{array}{c}\text { Beta-306723 } \\
\text { GrA-59632 }\end{array}$ & $\begin{array}{l}6950 \pm 50 \\
7620 \pm 40\end{array}$ & $\begin{array}{l}7925-7680 \\
8518-8365\end{array}$ \\
\hline & V & $M M D$ & $\begin{array}{l}H \\
C\end{array}$ & $\begin{array}{c}\text { Beta-306725 } \\
\text { GrA-59633 }\end{array}$ & $\begin{array}{l}7860 \pm 40 \\
8015 \pm 45\end{array}$ & $\begin{array}{l}8933-8546 \\
9020-8716\end{array}$ \\
\hline \multirow[b]{2}{*}{ Espantalobos } & $c$ & $M G$ & $C$ & Beta-361624 & $7390 \pm 40$ & 8321-8046 \\
\hline & $e$ & $M M D$ & $C$ & Beta-361625 & $7900 \pm 50$ & $8975-8547$ \\
\hline \multirow[t]{2}{*}{ Forcas-II } & $\begin{array}{l}I V \\
I I \\
I I\end{array}$ & $M G$ & $\begin{array}{l}H \\
H \\
C\end{array}$ & $\begin{array}{c}\text { Beta-290932 } \\
\text { Beta } 250944 \\
\text { GrN-22686 }\end{array}$ & $\begin{array}{l}7000 \pm 40 \\
7150 \pm 40 \\
7240 \pm 40\end{array}$ & $\begin{array}{l}7935-7735 \\
8031-7871 \\
8163-7978\end{array}$ \\
\hline & $I b$ & $M M D$ & $C$ & Beta-59997 & $8650 \pm 70$ & $9887-9520$ \\
\hline Filador & 2 & $M M D$ & $\begin{array}{l}C \\
C\end{array}$ & $\begin{array}{l}A A-13411 \\
O x A-8658\end{array}$ & $\begin{array}{l}8150 \pm 90 \\
8515 \pm 60\end{array}$ & $\begin{array}{l}9405-8778 \\
9594-9422\end{array}$ \\
\hline
\end{tabular}

Tabla 7: Fechas C14 (desviación < 100) del Mesolítico de Muescas y Denticulados (MMD) y del Mesolítico Geométrico (MG) de la orilla izquierda del Ebro / Denticulate (MMD) and Geometric (MG) Mesolithic C14 dates (standard deviation < 100) from left bank sites of the Ebro River. 


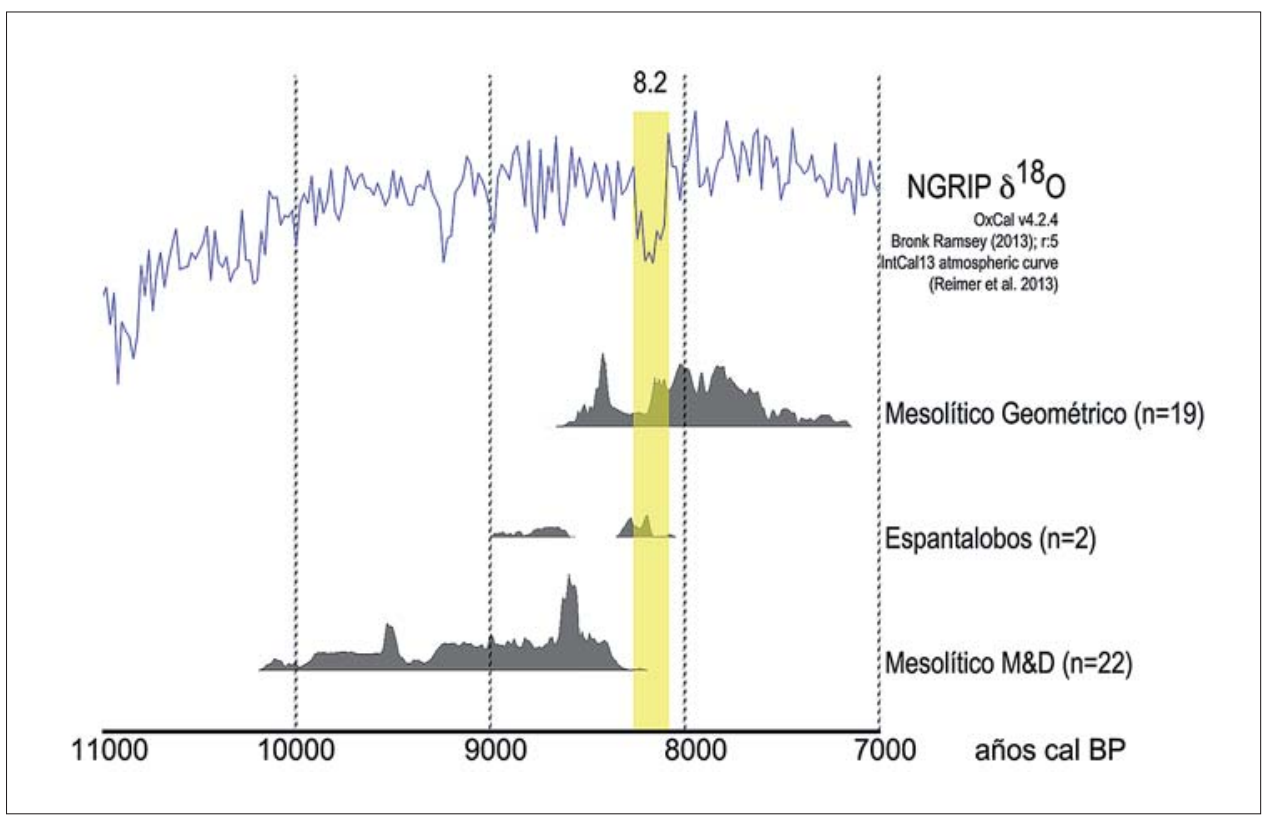

Fig. 7. Situación de las fechas C14 de Espantalobos entre los conjuntos de Muescas y Denticulados (abajo) y Geométricos (arriba) de la margen izquierda del Ebro (Tabla 7) / The C14 dates from Espantalobos between the assemblages of Denticulate (below) and Geometric (above) Mesolithic from the left bank of the Ebro River (Table VII).

El nivel c, como ya se ha dicho, no plantea dudas para su asignación cronocultural: sus materiales y la datación disponible casan sin problemas con el Mesolítico Geométrico, y dentro de este con su fase A, caracterizada por el predominio de los trapecios de retoque abrupto (ALDAY y CAVA, 2009; UTRILLA et al. 2009), siendo los tipos de Espantalobos alargados y con uno o dos lados cóncavos. La fecha obtenida lo relaciona con el llamado evento 8.2, una de las principales crisis climáticas del Holoceno, que se refleja en los registros polínicos del Valle del Ebro más por su aridez que por el descenso de las temperaturas. El intervalo 8321-8046 cal BP proporcionado por una muestra de carbón del nivel c (Tabla 1) insertaría la ocupación humana en este momento. Como ya se ha dicho, al ser imposible obtener colágeno de los huesos, se escogió un único carbón (procedente de un hogar) que fue identificado como Juniperus sp., lo cual ha podido repercutir en la fecha obtenida: por su lento crecimiento no se considera un taxón idóneo para obtener dataciones, si bien la muestra correspondía a una rama de pequeño calibre. Con todas las precauciones mencionadas respecto a la materia datada y a pesar de que los datos antracológicos son preliminares (parcialmente obtenidos sobre 10 registros de los 137 disponibles, limitados espacialmente a un solo cuadro), se puede aventurar que el retroceso de taxones mesófilos como el arce (Tabla 6) y el aumento de las frecuencias de aparición de especies xéricas, estuvieran reflejando esa crisis de aridez.

La amplia red de abrigos rocosos que se conocen en la cuenca del Ebro con ocupaciones mesolíticas y/o neolíticas (ALDAY et al. 2012 y 2014; MONTES y ALDAY, 2012) no puede explicar todo el sistema de ocupación del territorio de estas etapas. Estos sitios suelen ser refugios de pequeño tamaño, capaces de albergar escasas decenas de personas, en los que la presencia de varias estructuras de hogares a diferentes alturas y dispersos en planta, como en Espantalobos, evidencian momentos de ocupación distintos aunque se localicen en un mismo nivel arqueológico. Esta reiteración de las visitas se traduce también en las fechas obtenidas: es normal que un mismo nivel arqueológico presente dataciones a lo largo de unos 200 años (o más), que reflejan ese uso recurrente y prolongado en el tiempo.

El asentamiento principal del grupo podría ser un campamento al aire libre, relativamente estable, quizás incluso un pequeño poblado de construcciones ligeras, que acogería a la mayoría del grupo durante todo el año. De este punto central se desgajarían pequeñas partidas, en momentos diferentes, para abastecer al grupo de determinados recursos: sílex y otras rocas para la renovación constante del instrumental lítico y otros usos (minerales de hierro para hacer saltar chispas; óxidos minerales como el ocre para elaborar pigmentos y también para el curtido de las pieles...); vegetales para la alimentación (frutos secos, setas, especies diversas, frutas....), elaboraciones de cordelería y cestería, instrumental en madera, astiles de los proyectiles... y, constantemente, para la obtención de combustible; las partidas de caza abastecerían al grupo de carne para el consumo, pero también de pieles para elaborar vestimentas, refugios, recipientes (odres...), de tendones para trenzar y por supuesto, de materias duras (huesos y cuernas) utilizadas para fabricar instrumentos (anzuelos, punzones, espátulas...) alternativos a los líticos y de madera.

La poca entidad de los refugios (tiendas) del campamento central o de las primitivas cabañas en caso de tratarse de un poblado, y la fuerte erosión experimentada en la zona central del Ebro dificultan enormemente su conservación hasta la actualidad, y más aún, su localización. Por eso, la mayoría de los yacimientos conocidos de estas 
épocas en la Cuenca del Ebro corresponden a lo que se consideran asentamientos de segundo orden, de tipo estacional, que en las zonas de sierra aprovechaban los resaltes rocosos para instalarse, en ocasiones sin más acondicionamiento que los hogares observados en Espantalobos y algún paraviento. Pero a menudo esos campamentos secundarios estarían también al aire libre, formados por una pequeña agrupación de tiendas, como la observada en el Cabezo de la Cruz, junto al Huerva (RODANÉS y PICAZO, 2009, 2013). La reducida visibilidad arqueológica de estos enclaves, menor incluso que la de los campamentos/poblados centrales, los hace prácticamente indetectables, salvo por un cúmulo de casualidades (en lo relativo a la conservación y a la investigación).

En este contexto, el enclave de Espantalobos podría ser interpretado, al igual que el resto de pequeños abrigos rocosos con ocupaciones similares, como un asentamiento estacional, dedicado a la explotación de uno o varios recursos concretos, que era recurrentemente ocupado por una pequeña partida de gente procedente de una población mayor, cuyo asentamiento principal distaría algunos kilómetros. Pero, ¿cuál era ese o esos recursos? La respuesta, siempre hipotética, hay que rastrearla en los materiales recuperados y en el entorno del asentamiento.

Es habitual achacar a estos sitios una especialización en la caza, dada la presencia de proyectiles y de restos de fauna. Pero esta es una inferencia demasiado simplista puesto que la presencia de proyectiles (las armaduras geométricas) no implica una especialización en la caza: fuera la que fuera la tarea principal (o tareas) desarrollada en el sitio, el grupo cazaría para subsistir, por lo que en todos los yacimientos de este tipo están presentes algunas armas y restos de la fauna consumida. No es la presencia de armamento lo definitorio, sino la proporción del mismo. En el escaso instrumental lítico recuperado en Espantalobos los geométricos son mayoría entre las piezas retocadas del nivel c, pero su proporción ha de ser doblemente considerada con prevención: por la escasez de la muestra y porque el propio sistema de enmangue (podrían insertarse varias armaduras en un mismo proyectil) implica la sobrerrepresentación de estas piezas. El resto de los elementos retocados son también muy escasos y ofrecen poca información respecto a las posibles funciones del sitio: sólo hay algunas muescas y denticulados y los 3 cantos trabajados, posibles choppers y rabot. Hay además algunas piezas esquirladas o con retoques aislados poco definidas. La presencia de los cantos y denticulados sugiere tareas sobre madera y vegetales sensu lato.

Tampoco la fauna recuperada permite la caracterización exclusiva del sitio como cazadero. En Espantalobos hay muy pocos restos de fauna mayor que justificaran esa interpretación, escasez que no parece responder sólo a los habituales problemas de conservación: los depósitos de estos abrigos (y los restos porosos que contienen, como los huesos) sufren procesos alternativos y extremos de humectación/secado y marcadas oscilaciones de temperatura que acaban por afectar a los restos óseos, que prácticamente desaparecen al "estallar" por las dilataciones consecuentes. En la reducida muestra de Espantalobos, buena parte de los conjuntos óseos recuperados son de conejo, mientras que los restos de macrofauna son minoritarios, y de momento apenas se ha identificado la presencia de ciervo en el nivel e y cabra en ambas capas. El predominio del conejo, especie propia del biotopo local, parece sugerir un tipo de caza prosaica, de mera subsistencia. Los restos de macromamíferos parecen indicar un entorno boscoso (ciervo) y el acceso a biotopos rocosos (cabra), pero al igual que las evidencias líticas, son demasiado escasos para permitir conclusiones definitivas sobre las estrategias socio-económicas.

Los trabajos en Espantalobos continuan en la actualidad: al redactar este texto se están estudiando ya los materiales recuperados en 2014, y está prevista la última y definitiva campaña en el verano de 2015.

\section{6.- AGRADECIMIENTOS}

Los autores desean agradecer a Isabelino Gracia, de Huesca, por la localización del yacimiento y la cesión de sus materiales; a Fernando Navajas por permitir el uso y difusión de las fotografías aéreas tomadas con paramotor; al Ayuntamiento de Quicena y a la Comarca de la Hoya de Huesca por su contribución económica y ayuda en la instalación de la infraestructura para la campaña; a los alumnos de licenciatura, grado, máster y/o doctorado de Historia y de Humanidades de la Universidad de Zaragoza que participaron en la excavación: T. Bernués, R. Caballero, P. Callizo, T. Catalán, L.M. García, J. Murillo, P. Sánchez, S. Sanz, M. Tarongi y T. Usieto. Este estudio se ha financiado también mediante el Proyecto de Investigación ministerial HAR2014-59042 (Transiciones climáticas y adaptaciones sociales en la Prehistoria de la Cuenca del Ebro) y el Grupo de Investigación del Gobierno de Aragón H07-PPVE (Primeros Pobladores del Valle del Ebro), y ha contado con el soporte del IUCA (Instituto Universitario de Ciencias Ambientales de la Universidad de Zaragoza). R. Domingo y $\mathrm{M}$. Alcolea son respectivamente, investigador Ramón y Cajal (ref: RyC2013-12613) y becaria predoctoral (ref: BES 2012-0553828).

\section{BIBLIOGRAFÍA}

ALDAY, A. y CAVA, A.

2006 La unidad de muescas y denticulados del Mesolítico en el País Vasco: la formalización de un modelo cultural, en ALDAY, A. (coord.) El Mesolítico de Muescas y Denticulados en la Cuenca del Ebro y en el litoral mediterráneo peninsular. 223-302. Memorias de Yacimientos Alaveses 11. Diputación Foral de Álava.

2009 El Mesolítico geométrico en Vasconia, en UTRILLA, P. Y MONTES, L. (eds.). El Mesolítico Geométrico en la Península Ibérica. 93-130. Monografías Arqueológicas. Prehistoria 44. Universidad de Zaragoza. 
ALDAY, A., MONTES, L. y BALDELLOU, V.

2012 El Neolítico en la Cuenca del Ebro, en ROJO, M., GARRIDO, R. y GARCÍA, I. (coords.). El Neolítico en la Península Ibérica y su contexto europeo. 291-331. Ediciones Cátedra, Madrid: 291-331.

\section{ALDAY, A., MONTES, L., UTRILLA, P. y DOMINGO, R.}

2014 The Mesolithic in the Ebro Basin, Spain, en Arias, P. y Cueto, M. (eds). Gathering in the South: Proceedings of the Eighth International Conference on the Mesolithic in Europe. Santander 13th-17th September, 2010. Oxbow, Oxford (e.p.).

CUCHÍ, J.A., MONTES, L., JUSTES, J. y LAFRAGÜETA, I.

2005 Roca y Agua. El condicionamiento del entorno y el desarrollo histórico de la ciudad de Huesca. Saldvie 5, 159-175

FORTEA, J.

1973 Los complejos microlaminares y geométricos del Epipaleolítico Mediterráneo español. Universidad de Salamanca.

GARCÍA-SIMÓN, L.M., y MANDADO, J.

2014 Rocas silíceas de la margen izquierda del Valle Medio del Ebro. Lucas Mallada 16, 89-118.

GONZÁLEZ SAMPÉRIZ, P., VALERO-GARCÉS, B.L., CARRIÓN, J.S., PEÑA-MONNE, J.L., GARCÍA-RUIIZ, J.M. y MARTII-BONO, C.

2005 Glacial and lateglacial vegetation in Northeastern Spain: New data and a review. Quaternary International 140-141, 4-20.

IGME

Mapa geológico de España 1:50.000 Hoja 323 (Zuera). http://www.igme.es/internet/Cartografia/cartografia/datos/ magna50/memorias/MMagna0323.pdf
MONTES, L.

2002 El abrigo epipaleolítico de Peña 14 (Biel, Zaragoza). Excavaciones 1999 y 2000. Saldvie 2, 67-73.

MONTES, L. y ALDAY, A.

2012 Enredados en la malla neolítica de la cuenca del río Ebro. Redes, continuidades y cambios. Rubricatum 5, 51-60.

MONTES, L., UTRILLA, P. y MAZO, C.

2006 El Epipaleolítico Macrolítico en Aragón en el contexto del Valle del Ebro y la Cataluña costera, en ALDAY, A (coord.), El mesolítico de muescas y denticulados en la cuenca del Ebro y el litoral mediterráneo peninsular (Vitoria, noviembre 2005). 193-223. Memorias de Yacimientos Alaveses, 11. Diputación Foral de Álava.

RODANÉS, J.M. y PICAZO, J.

2009 La cabaña mesolítica del Cabezo de la Cruz (La Muela, Zaragoza), en Utrilla, P. y Montes, L. (eds.). El Mesolítico Geométrico en la Península Ibérica. 327-341. Universidad de Zaragoza. Monografías Arqueológicas. Prehistoria 44.

2013 El campamento mesolítico del Cabezo de la Cruz. La Muela, Zaragoza. Universidad de Zaragoza. Monografías Arqueológicas. Prehistoria 45.

UTRILLA, P., MONTES, L., MAZO, C., MARTíNEZ-BEA, M., y DO$\mathrm{MINGO}, \mathrm{R}$

2009 El Epipaleolítico geométrico en Aragón, en UTRILLA, P. Y MONTES, L. (eds.). El Mesolítico Geométrico en la Península Ibérica. 131-190. Monografías Arqueológicas. Prehistoria 44. Universidad de Zaragoza.

VALERO-GARCÉS, B.L., GONZÁLEZ-SAMPERIZ, P., NAVAS, A., MACHÍN, J., DELGADO-HUERTAS, A., PEÑA-MONNÉ, J.L., SANCHO-MARCES, C., STEVENSON, T., y DAVIS, B.A.S.

2004 Paleohydrological fluctutations and steppe vegetation during the last glacial maximum in the Central Ebro valley (NE Spain). Quaternary International 122, 43-55. 
